\title{
Comparison of muscle activation of the transversus abdominis and muscle strength between individuals with low back pain, herniated disc and healthy individuals: a cross-sectional study.
}

Clecio Souza ( $\nabla$ cleciogabriel1@hotmail.com )

Federal University of Rio Grande do Norte

Sanderson Assis

Federal University of Rio Grande do Norte

Karinna Costa

Federal University of Rio Grande do Norte

Yago Medeiros

Faculty of Estacio do Rio Grande do Norte

Liane Macedo

Federal University of Rio Grande do Norte

\section{Research Article}

Keywords: low back pain, herniated disc, tranversus abdominis

Posted Date: December 14th, 2020

DOl: https://doi.org/10.21203/rs.3.rs-116631/v1

License: (c) (1) This work is licensed under a Creative Commons Attribution 4.0 International License.

Read Full License 


\section{Abstract}

BACKGROUND: Low back pain and disc herniation are common problems in the world population, being characterized by discomfort in the region of the spine, resulting in functional capacity and quality of life reduced. Some of the causes of these conditions seem to be associated with the biomechanical imbalance of the muscles that act in the spine. There are methods to assess the level of activation and strength of the stabilizing muscles of the spine, such as the Pressure Biofeedback Unit (PBU). This study aims to compare the level of activation of the transverse abdomen muscle and back strength in healthy, low back pain and herniated disc individuals.

METHODOS: a cross-sectional study was carried out with 30 men that were homogeneously distributed in three groups: healthy $(\mathrm{HG})$, with low back pain (LBPG) and with herniated disc (HDG). The primary outcomes were the level of activation of the transversus abdominis, assessed by PBU, and back strength, assessed by dynamometry. Pain, flexibility and disability were evaluated as secondary outcomes.

RESULTS: The mean age of the participants in this study was $30.47 \pm 9.74$ years. Regarding the activation of the transversus abdominis, no differences were found between groups $(p=0.155)$. For strength, LBPG and HDG were different compared to HG ( $p=0.028$ and $p=0.045$, respectively). Pain was different between the HG and both LBPG and HDG (all $p<0.001$ ). Regarding flexibility, no differences ( $p>$ $0.05)$ were found. The HDG had the highest disability score and was statistically different of the HG $(p=$ $0.005)$, but with no difference from LBPG $(p=0.087)$.

CONCLUSION: the activation of the tranversus abdominis is similar between healthy, non-specific back pain and herniated disc individuals; however, the latter presents a reduced level of strength and more disability.

\section{Introduction}

Low Back Pain (LBP) is a common condition in the world population [1]. It is one of the main causes of musculoskeletal diseases and demand for health care [2,3]. More than $80 \%$ of the population will experience this symptom at some time in their lives; of those, $95 \%$ will recover within a few months, while the others will develop chronic LBP [4].

LBP can be classified as specific, those that have a defined cause, and non-specific, when the pathoanatomical cause cannot be determined [5]. The most common condition among people with specific back pain is disc herniation; however, the majority is classified as non-specific [5,6].

It has been demonstrated that individuals with LBP present musculoskeletal dysfunctions, such as delayed recruitment, insufficient muscle control, and reduced cross-sectional area, strength, endurance, and flexibility $[7,8,9,10]$. The musculoskeletal system composing the core muscles related to the spine consists of global muscles (rectus abdominis, external oblique, anterior fibers of the internal oblique, and the thoracic portion of the iliocostalis) and local stabilizing muscles (multifidus, psoas major, transversus 
abdominis, quadratus lumborum, diaphragm, internal oblique muscles, the lumbar part of the iliocostalis, and the longissimus muscles) [11]. The transversus abdominis seems to be the key stabilizing muscle, and its dysfunctions are associated with the development of LBP $[9,12]$.

One of the methods used to assess these muscles is the pressure biofeedback unit (PBU). This is a noninvasive technique considered valid, reliable, low-cost, and easy to handle that uses the tension generated by the muscle contractions to measure their activity [13]. The measurement of strength is another effective way to evaluate the functional ability of the back muscles. The dynamometry is a valid and reliable instrument that can be used and provides objective strength values [14]. Although these devices are widely used to evaluate back pain, there are no studies comparing individuals with specific and nonspecific back pain.

Thus, this study aimed to compare the activation of the transversus abdominis and the back muscle strength between self-reported healthy individuals, individuals with non-specific LBP, and individuals with disc herniation.

\section{Methods}

This is a cross-sectional study that was carried out in the city of Natal (Rio Grande do Norte - Brazil) from July to November 2016. The convenience sample was composed of male individuals aging between 25 to 60 years and intentionally divided into three groups: Healthy Group (HG), Low Back Pain Group (LBPG), and Herniated Disc Group (HDG). Those individuals with non-specific LBP for at least three months were included in the LBPG. For the HDG, the individuals should have a clinical diagnosis of lumbar disc herniation and magnetic resonance image with up to six months of validity after diagnosis. For the HG, those who did not have herniated discs or low back pain in the past six months were included. The individuals who have undergone any physical therapy treatment in the last three months or did not perform the evaluation procedures correctly were excluded from the study.

An assessment form prepared by the researchers and containing individual, clinical, and and occupational data regarding weekly working hours was used to evaluate the participants. The pain was evaluated using the visual analog scale (VAS) [15], while flexibility was assessed using the Schober test [16], and disability through the Roland-Morris questionnaire [17]. A 300kgf dorsal dynamometer (KRATOS ${ }^{\circledR}$ ) was used to assess the back muscle strength [14] and the activation of the transversus abdominis was assessed using the PBU [13].

To measure the back muscle strength, the participants were positioned with feet fully supported on the dynamometer platform, and knees extended. The trunk should be flexed at $120^{\circ}$, the cervical spine aligned to the trunk, and the dynamometer arms at knee-length. While holding the dynamometer arm with elbows extended and no shoulder movement, the participants were asked to perform three maximal voluntary isometric contractions (MVIC) for trunk extension, during 5 seconds, with a 60-s interval between each repetition (Fig. 1) and the highest value was used for data analysis. 
The PBU was performed using a sphygmomanometer with a pressure range between 0 and $300 \mathrm{mmHg}$. For this, the participants were positioned prone on a plinth with the sphygmomanometer below the lower abdomen (at the level of the umbilicus), arms kept alongside the body, feet placed over the plinth, and head rotated to the right (Fig. 2). The sphygmomanometer was inflated to $70 \mathrm{mmHg}$, and the participants were instructed to move the abdominal wall uptwards and inwards without moving the spine and pelvis. This position was maintained for 10 seconds. An excellent contraction was considered if a variation of 4-6 $\mathrm{mmHg}$ was observed [18]. A variation above or below this pressure corresponded to an insufficient contraction.

All statistical analyses were performed using the Statistical Package for the Social Sciences (SPSS) software, version 22.0 (IBM Corp., USA). Data are shown as mean \pm standard deviation, and data normality was performed using the Shapiro-Wilk test. One-way ANOVA with Tukey's posthoc test was performed to determine the homogeneity of the initial values and compare the differences between groups (HG, LBPG, and HDG) for the following variables: pain, flexibility, disability, and strength. ChiSquare test was used to analyze categorical variables. A significance level of $5 \%$ (two-tailed) was considered.

This study was approved by the Research Ethics Committee of the Federal University of Rio Grande do Norte (number 1659839), and conducted respecting the resolution 466/2012/CNS/MS/CONEP of the National Health Council and the World Medical Association Declaration of Helsinki. All individuals were aware of the research's objectives and procedures and signed an informed consent form with permission to publish identification images in an open access publication.

\section{Results}

Thirty individuals, ten in each group, were selected and evaluated. There were no sample losses. The sample characterization and homogeneity are shown in Table 1. 
Table 1

Sample characterization and homogeneity of the groups

\begin{tabular}{|c|c|c|c|c|}
\hline & & Mean & Standard Deviation & p-value \\
\hline \multirow[t]{4}{*}{ Age (years) } & $\mathrm{HG}$ & 31.4 & 8.1 & \\
\hline & LBPG & 23.2 & 2.2 & \\
\hline & HDG & 36.8 & 11.4 & \\
\hline & Total & 30.5 & 9.7 & 0.004 \\
\hline \multirow[t]{4}{*}{ BMI $\left(\mathrm{kg} / \mathrm{m}^{2}\right)$} & $H G$ & 26.4 & 2.5 & \\
\hline & LBPG & 27.2 & 6.7 & \\
\hline & HDG & 27.7 & 2.9 & \\
\hline & Total & 27.1 & 4.3 & 0.806 \\
\hline \multirow[t]{4}{*}{ Weekly work hours } & $\mathrm{HG}$ & 33.1 & 10.8 & \\
\hline & LBPG & 28.2 & 12.9 & \\
\hline & HDG & 34.3 & 13.0 & \\
\hline & Total & 31.9 & 12.1 & 0.511 \\
\hline
\end{tabular}

Pain was significantly different between the HG and both the LBPG and HDG (all $p<0.001$ ). Regarding flexibility, no significant differences $(p>0.05)$ were found. The HDG had the highest disability score and was statistically different from the HG $(p=0.005)$, but not different from the LBPG $(p=0.087)$. For strength, both the LBPG and the HDG were different compared with the HG $(p=0.028$ and $p=0.045$, respectively), according Table 2. 
Table 2

Table 2. Pain, flexibility, disability, and strength data of the three groups studied.

\begin{tabular}{|lllll|}
\hline Variables & HG & LBPG & HDG & P value \\
& Mean (SD) & Mean (SD) & Mean (SD) & \\
\hline Pain & $0.4(0.8)$ & $4.0(1.4)$ & $4.7(2.3)$ & $<0.001$ \\
\hline Flexibility & $7.1(1.1)$ & $6.2(1.4)$ & $5.9(0.8)$ & 0.094 \\
\hline Disability & $0.7(1.2)$ & $2.9(1.9)$ & $6.9(6.6)$ & 0.007 \\
\hline Strength & $119.2(21.2)$ & $86.3(30.7)$ & $88.9(27.5)$ & 0.018 \\
\hline $\begin{array}{l}\text { Values of mean and standard deviation (SD) of all variables and groups and ANOVA comparison } \\
\text { results between groups. }\end{array}$ & & & \\
\hline
\end{tabular}

Regarding the activation of the transversus abdominis, $60 \%$ of the HG participants had excellent activation, while $30 \%$ and $20 \%$ were excellent in the LBPG and HDG, respectively. Besides that, no significant differences were found between groups $(p=0.155)$ (Table 3$)$.

Table 3

Transversus abdominis muscle activation in the three groups studied.

\begin{tabular}{|llll|}
\hline \multicolumn{3}{|c|}{ Transversus abdominis activation } \\
\hline & Excellet contranction & Insufficient contranction & $\mathbf{p}$ \\
\cline { 2 - 3 } & $\mathbf{n}(\%)$ & $\mathbf{n}(\%)$ & \\
\hline Group & & & \\
\hline Healthy & $6(60,0)$ & $4(40,0)$ & 0,155 \\
\hline Low Back Pain & $3(30,0)$ & $7(70,0)$ & $8(80,0)$ \\
\hline Herniated Disc & $2(20,0)$ & & 0 \\
\hline
\end{tabular}

\section{Discussion}

The purpose of this study was to compare the activation of the transversus abdominis and the back muscle strength between healthy individuals, individuals with non-specific low back pain, and individuals with disc herniation.

The mean age was significantly different between groups, and the HDG had a higher value when compared with the HG and LBPG. Thus, age can be considered an important factor since older individuals are more prone to developing degenerative changes in the spine. This notion corroborates 
with Dammers [19] and Taylor et al. [20], which showed that spinal degeneration increases with age, and starts in both the caudal region (caused by the loss of proteoglycans) and in the upper and lower discs of the lumbosacral region, due to its proximity to the sacrum. Moreover, disc herniation is uncommon in the first decades of life, being more prevalent in the subsequent four decades as a result of spinal overloading [21].

The body mass index and the working hours evaluated in this study were homogeneous for all participants. These factors are associated with spinal problems [22] due to the overload imposed by the time of work, prolonged static position, lifting of intermittent loads [23], and the own body structure in the case of overweight and obesity, resulting in musculoskeletal imbalances [24].

Although the HDG presented the greater instability to maintain a sustained contraction of the transversus abdominis, no significant differences were observed between the three groups studied. The instability observed in the HG can also be highlighted since its presence is probably involved in the complexity of low back pain[25].

Previous studies have shown that inadequate activation of the transversus abdominis is associated with back pain $[26,27,28]$, and its ineffective contraction may lead to hypotrophy and reduced firing rate [29, 30]. Also, those individuals with a previous history of asymptomatic back pain and flares present deficits in the transversus abdominis activation [31,32].

The reliability and reproducibility of the PBU to measure the transversus abdominis activity in both healthy $[33,34]$ and individuals with non-specific LBP [35] has been evaluated in previous studies and showed good results. However, more recently, the same research group conducted another study to verify the concurrent validity between PBU and surface electromyography (EMG) in patients with chronic LBP and found a low specificity and sensitivity of the PBU to evaluate the transversus abdominis activation [36]. The reasons for this result were probably related to the depth of the muscle, the EMG crosstalk, and the different purposes of these tools since EMG evaluates the electrical muscle activity and PBU assesses the abdominal displacement caused by abdominal muscle contraction.

Regarding the back strength during spine extension, a significant difference between the LBPG and HG was found, but with no differences between LBPG and HDG. This fact was probably influenced by the pain level caused by the LBP. The fear of pain during maximum effort is an important factor taken into account by the patients. Therefore, those without pain felt safer and reached high strength values (119.2 $\pm 21.2 \mathrm{kgf})$, close to the reference values $(114,0 \pm 25,4 \mathrm{kgf})$ described by Eichinger et al. [14].

With regards to flexibility, there was no difference between groups, showing that this variable is not associated with low back pain or herniated disc, and corroborating with Graup et al. [21], who described no association between lumbar flexibility and pain in this region. However, pain is a predisposing factor for decreased lumbar flexibility, as stated by Toscano [37], who showed that the range of motion was associated with acute or chronic LBP relief. As expected, back pain was not different between healthy individuals and those with specific or non-specific LBP. 
Disability has been a widely used criterion to evaluate patients with LBP, and the Rolland Morris questionnaire is a valid and well-accepted instrument for this outcome [38]. In the present study, it was observed that the HDG showed more disability than the LBPG and HG. Although disability has a direct relationship with pain, and both the LBPG and HDG presented significant pain levels, its conception in chronic conditions is multifactorial and does not present a linear and homogeneous behaviour [39]. This may explain why no differences were found in the LBPG. Also, according to Porchet et al. [40], the herniated disc severity is related to disability; thus, it can be concluded that individuals with disc herniation present more disability despite having pain levels similar to those with LBP.

The present study has some limitations. The cross-sectional design did not allow a direct causal inference, and the reduced sample may have minimized the interaction effects between groups. Moreover, both the PBU and the Schober test still present conflicting results, thus requiring further studies to confirm their validity. Further studies with larger samples and long-term follow-ups are needed to investigate the real effectiveness of these instruments.

\section{Conclusion}

We can conclude that the activation of the tranversus abdominis is similar between healthy, non-specific back pain and herniated disc individuals; however, the latter presents a reduced level of strength and more disability.

\section{Declarations}

\section{Ethics approval and consent to participate}

This study was approved by the Research Ethics Committee of the Federal University of Rio Grande do Norte (number 1659839), and conducted respecting the resolution 466/2012/CNS/MS/CONEP of the National Health Council and the World Medical Association Declaration of Helsinki. All individuals were aware of the research's objectives and procedures and signed an informed consent form with permission to publish identification images in an open access publication.

\section{Availability of data and materials}

The data for this research are available in the database attached in the related files section.

\section{Conflict of interests}

The authors declare that they have no conflict of interests.

\section{Funding}

The postgraduate program in Rehabilitation Sciences at the Federal University of Rio Grande do Norte supported the researchers and financed the costs of translation and final writing of the manuscript. This 
study was financed in part by the Coordenação de Aperfeiçoamento de Pessoal de Nível Superior - Brazil (CAPES) - Finance Code 001.

\section{Authors' contributions}

CGS was responsible for the study design and data collection. Performed data analysis and final writing.

YCM conducted the data collection and the writing of the manuscript.

SJCA performed statistical analysis and participated in the writing of the manuscript.

KSAC organized the data and methodological aspects for submission of the manuscript.

LBM reviewed the manuscript and the translation criteria.

All authors approved this final version of the manuscript.

\section{Acknowledgements}

Not applicable

\section{References}

1. Hoy D, Bain C, Williams G, March L, Brooks P, Blyth F, et al. A systematic review of the global prevalence of low back pain. Arthritis Rheum. 2012;64(6):2028-37.

2. GBD 2016 Disease and Injury Incidence and Prevalence Collaborators. Global, regional, and national incidence, prevalence, and years lived with disability for 328 diseases and injuries for 195 countries, 1990-2016: a systematic analysis for the Global Burden of Disease Study 2016. Lancet 2017; 390: 1211-59.

3. Andersson GBJ. Epidemiological features of chronic low-back pain. Lancet 1999; 354: 581-85.

4. Freburger JK, Holmes GM, Agans RP, Jackman AM, Darter JD, Wallace AS, et al. The rising prevalence of chronic low back pain. Arch Intern Med. 2009;169(3):251-8.

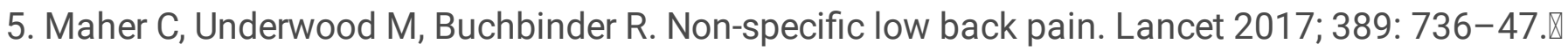

6. Chiu CC, Chuang TY, Chang KH, Wu CH, Lin PW, and Hsu WY. The probability of spontaneous regression of lumbar herniated disc: a systematic review. Clinical Rehabilitation 2015: 29(2), 184195.

7. Malliou P, Gioftsidou A, Beneka A, Godolias G. Measurements and evaluations in low back pain patients. Scand J Med Sci Sport. 2006;16(4):219-30.

8. Demoulin C, Crielaard JM, Vanderthommen M. Spinal muscle evaluation in healthy individuals and low-back-pain patients: a literature review. Jt Bone Spine. 2007;74(1):9-13.

9. Hogdes PW, Richardson Inefficient muscular stabilization of the lumbar spine associated with low back pain. A motor control evaluation of the transversus abdominis. Spine 1996a; 
21(22): 2640-2650.

10. Ferreira PH, Ferreira ML, Maher CG, Refshauge K, Herbert R, Hodges PW. Changes in recruitment of transversus abdominis correlate with disability in people with chronic low back pain. Br J Sports Med 2010;44:1166-72.

11. Adukota, V, Nadler, SF. Core Strengthening. Am J Phys Med Rehabil 85 (1): 86-92, 2004.

12. Russo, M., Deckers, K., Eldabe, S., Kiesel, K., Gilligan, C., Vieceli, J., \& Crosby, P. (2018). Muscle control and non-specific chronic low back pain. Neuromodulation: Technology at the Neural Interface, 21(1), $1-9$.

13. Lima POP, Oliveira RR, Costa LOP, Laurentino GEC. Measurement properties of the pressure biofeedback unit in the evaluation of transversus abdominis muscle activity: a systematic review. Physiotherapy 2011: 97(2), 100-106.

14. Eichinger FLF, Soares AV, Carvalho Júnior JM, Gevaerd MS, Domenech SC, Borges Júnior NG. Lumbar dynamometry: a functional test for the torso. Rev Bras Med Trab. 2016;14(2):120-6.

15. Hawker, G.A., Mian, S., Kendzerska, T., French, M. Measures of adult pain: Visual Analog Scale for Pain (VAS Pain), Numeric Rating Scale for Pain (NRS Pain), McGill Pain Questionnaire (MPQ), ShortForm McGill Pain Questionnaire (SF-MPQ), Chronic Pain Grade Scale (CPGS), Short Form-36 Bodily Pain Scale SF. Arthritis Care Res. 2011;63(11):240-252. https://doi.org/10.1002/acr.20543

16. Williams R, Binkley J, Bloch R, Goldsmith $\mathrm{CH}$, Minuk T. Reliability of the modified-modified Schöber and double inclinometer methods for measuring lumbar flexion and extension. Phys Ther. 1993;73(1):33-44

17. Roland, M., Morris, R. A Study of the Natural History of Back Pain: Part IDevelopment of a Reliable and Sensitive Measure of Disability in Low-Back Pain. Spine. 1983; 8(2):141-144.

18. Costa LOP, Costa LCM, Cançado RL, Oliveira WM, Ferreira PH. Confiabilidade do teste palpatório e da unidade de biofeedback pressórico na ativação do músculo transversal abdominal em normais. Acta Fisiátrica. 2004; 11 (3): 101-5.

19. Dammers R, Koehler PJ. Lumbar Disc Herniation: Level Increases with Age. Surg Neurol Dammers and Koehler 2002;58:209-13.

20. Taylor TK et al. Spinal biomechanics and aging are major determinants of the proteoglycan metabolism of intervertebral disc cells. Spine 2000;25:3014-20.

21. Graup s, Bergmann MLA, Bergmann GG. Prevalência de dor lombar inespecífica e fatores associados em adolescentes de Uruguaiana/RS. rev bras ortop .2014;49(6):661-667 663.

22. Iguti AM, Hoehne EL. Occupational low back pain. Rev. bras. saúde ocup. 2003; 28(107/108):73-89.

23. Tsai SP, Gilstrap EL, Cowle SR et al. Personal and Job Characteristics of Musculoskeletal Injuries in an Industrial Population. Journal of Occupational Medicine. 1992;34(6):606-612.

24. Burdof, A. Exposure assessment of risk factors for disorders of the back in occupational epidemiology. Scandinavian Journal of Work and Environmental Health. 1992; 18:1-9. 
25. Reeves NP, Jaap JC, Van Dieën H, Kawchuk G, Hodges PW. Are Stability and Instability Relevant Concepts for Back Pain? J Orthop Sports Phys Ther. 2019; 49(6):415-424.

26. Hodges PW, Richardson CA. Inefficient muscular stabilization of the lumbar spine associated with low back pain: a motor control evaluation of transversus abdominis. Spine. 1996;21(22):2640-50

27. Hides J, Wilson S, Stanton W, McMahon S, Keto H, McMahon K, et al. An MRI investigation into the function of the transversus abdominis muscle during "drawing-in" of the abdominal wall. Spine. 2006;31(6):175-8.

28. Richardson CA, Snijder CJ, Hides JA, Damen L, Pas MS, Stom J. The relationship between the transversus abdominis muscles, sacroiliac joint mechanics, and low back pain. Spine. 2002;27(4):399-405.

29. Richardson C, Hodges P, Hides J. Therapeutic exercise for lumbopelvic stabilization: a motor control approach for the treatment and prevention of low back pain. 2nd ed. London: Churchill Livingstone; 2004.

30. Gouveia KMC, Gouveia EC. O músculo transverso abdominal e sua função de estabilização da coluna lombar. Fisiot. Mov. 2008;21(3):45-50.

31. Cairms MC, Harrison K, Wright C. Pressure biofeedback: A useful tool in the quantification of abdominal muscular dysfunction? Physiother. 2000;86:127-38.

32. França FR, Burke TN, Hanada ES, Marques AP. Segmental stabilization and muscular strengthening in chronic low back pain - a comparative study. Clinics. 2010; 65(10): 1013-1017.

33. Figueiredo MK, Chaves Júnior IP, Figueiredo VGC, Costa LOP, Costa LCM. Estudo da confiabilidade intra e entre-examinadores da unidade de biofeedback pressórico na medida da contração do músculo transverso abdominal. R. bras. Ci e Mov. 2005; 13(4): 93-100.

34. Costa LOP, Costa LCM, Cancado RL, Oliveira WM, Ferreira PH. Short report: intra-tester reliability of two clinical tests of transversus abdominis muscle recruitment. Physiother Res Int. 2006;11(1):48-50.

35. Lima POP, Oliveira RR, Moura Filho AG, Raposo MCF, Costa LOP, Laurentino GEC. Reproducibility of the pressure biofeedback unit in measuring transversus abdominis muscle activity in patients with chronic nonspecific low back pain. J Bodyw Mov Ther. 2012;16(2):251-7.

36. Lima POP, Oliveira RR, Moura Filho AG, Raposo MCF, Costa LOP, Laurentino GEC. Concurrent validity of the pressure biofeedback unit and surface electromyography in measuring transversus abdominis muscle activity in patients with chronic nonspecific low back pain. Rev. bras. fisioter. 2012; 16(5):389-95.

37. Toscano JJO, Egypto EP. A influência do sedentarismo na prevalência de lombalgia. Rev Bras MedEsporte vol.7 no.4 Niterói Jul./Aug. 2001.

38. Nusbaum L, Natour J, Ferraz MB, Goldenberg J. Translation, adaptation and validation of the RolandMorris questionnaire-Brazil Roland-Morris. Braz J Med Biol Res. 2001;34(2):203-10.

39. Weigl M, Cieza A, Cantista P, Reinhardt JD, Stucki G. Determinants of disability in chronic musculoskeletal health conditions: a literature review. Eur J Phys Rehabil Med 2008;44:67-79. 
40. Porchet, F., Wietlisbach, V., Burnand, B., Daeppen, K., Villemure, J. G., \& Vader, J. P. (2002). Relationship between severity of lumbar disc disease and disability scores in sciatica patients. Neurosurgery, 50(6), 1253-1260.

\section{Figures}

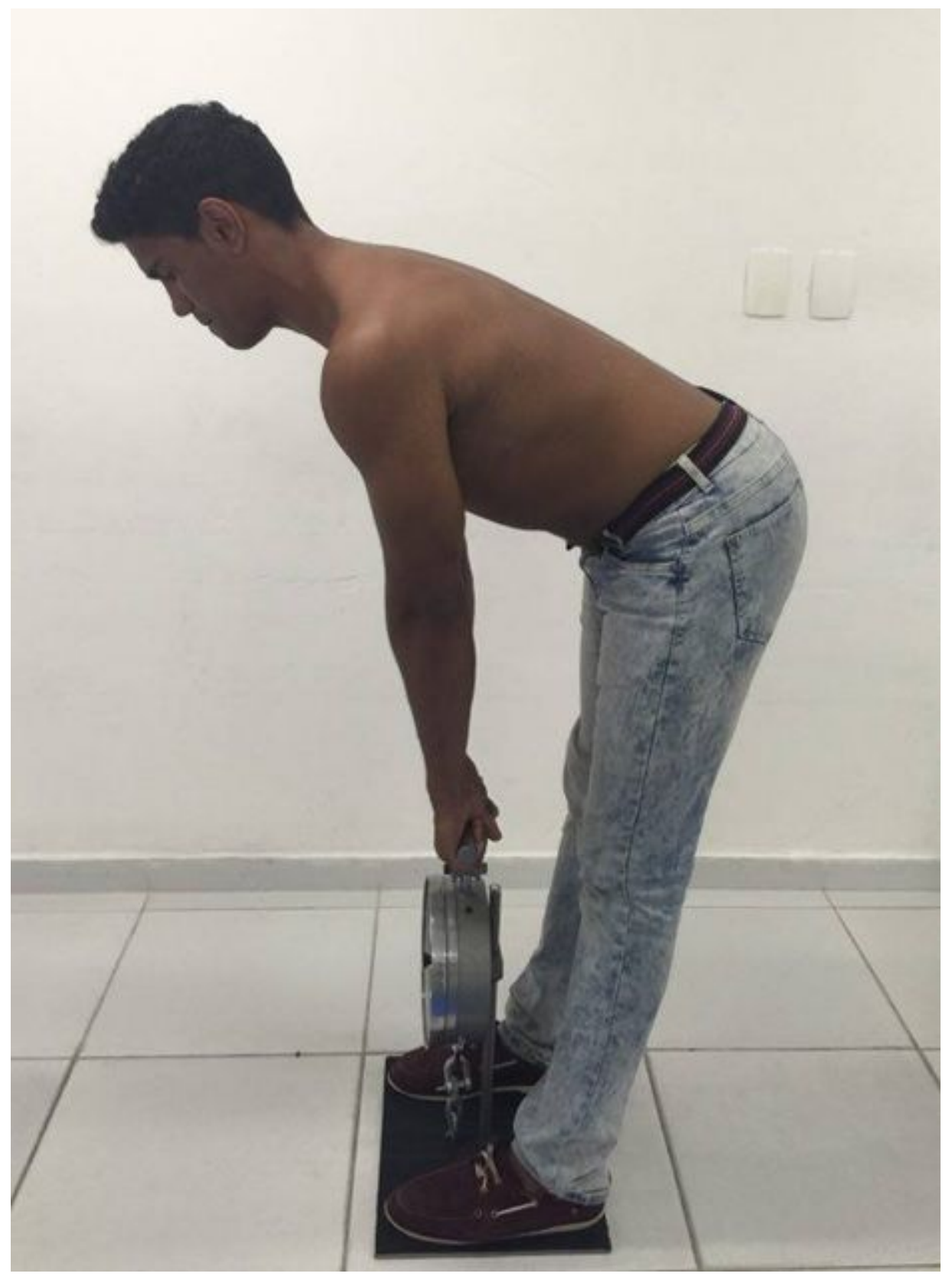

Figure 1

Assessment of the back muscle strength. 


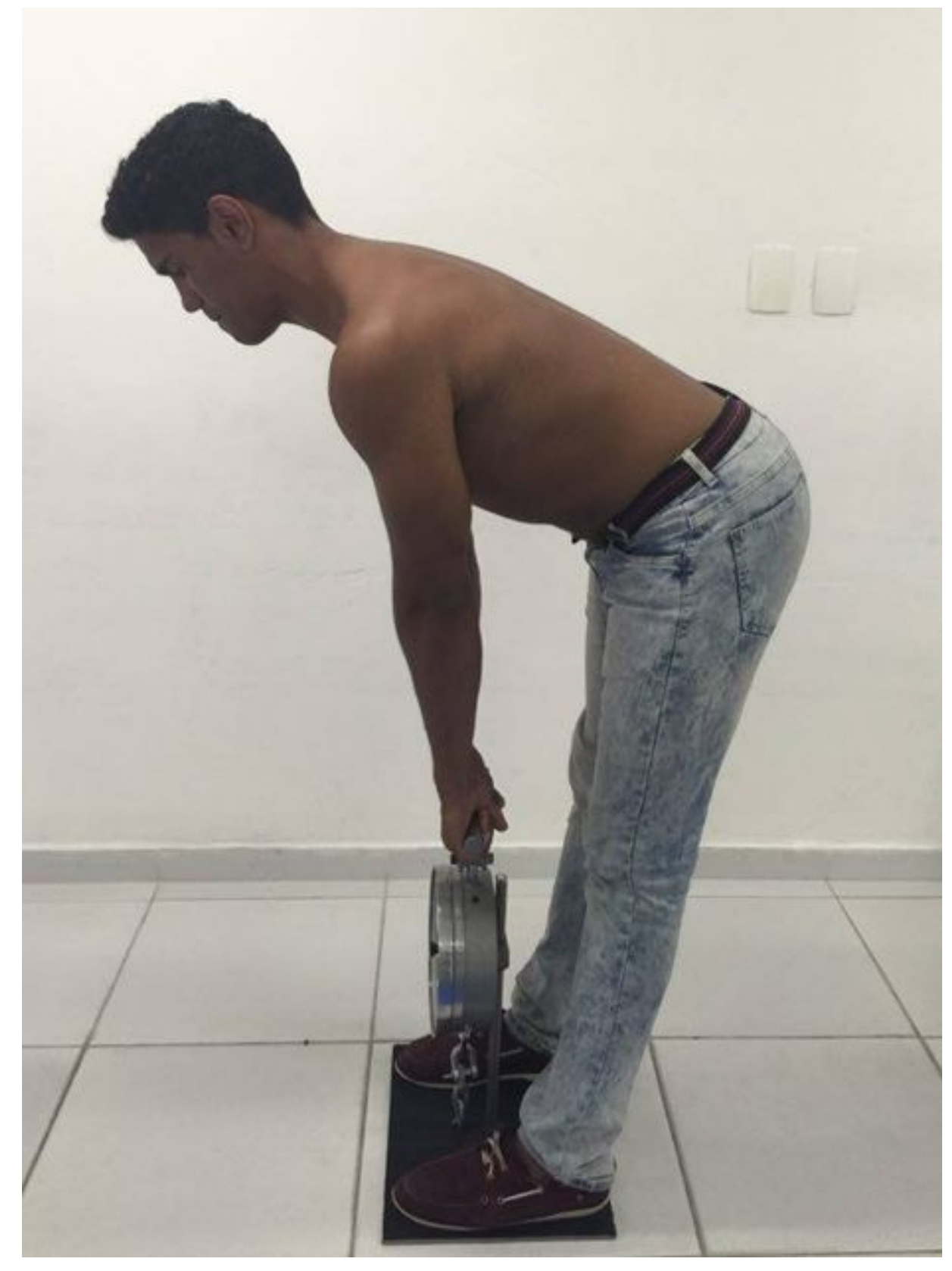

Figure 1

Assessment of the back muscle strength. 


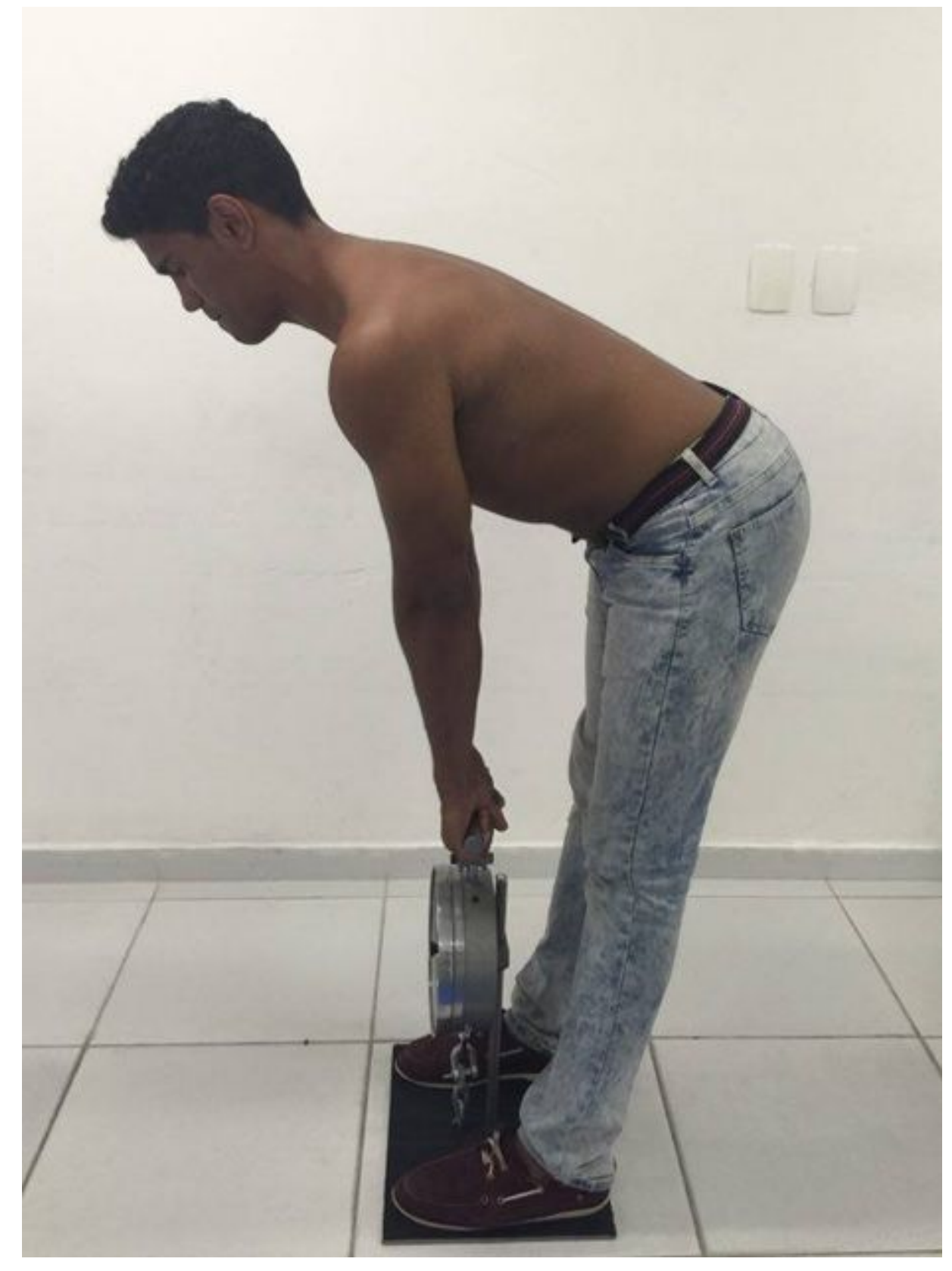

Figure 1

Assessment of the back muscle strength. 


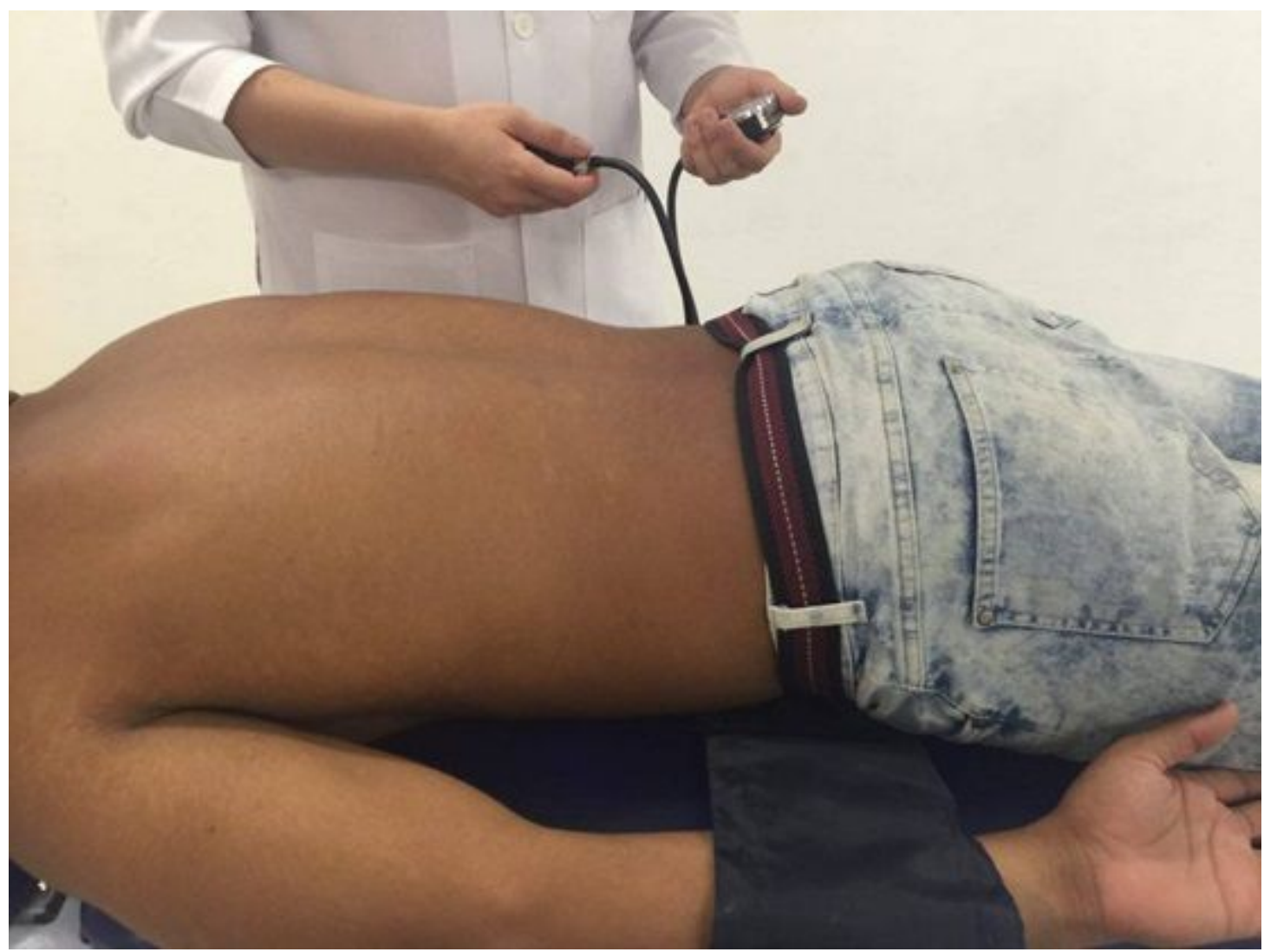

Figure 2

Muscle activation test for transversus abdominis using a Pressure Biofeedback Unit.

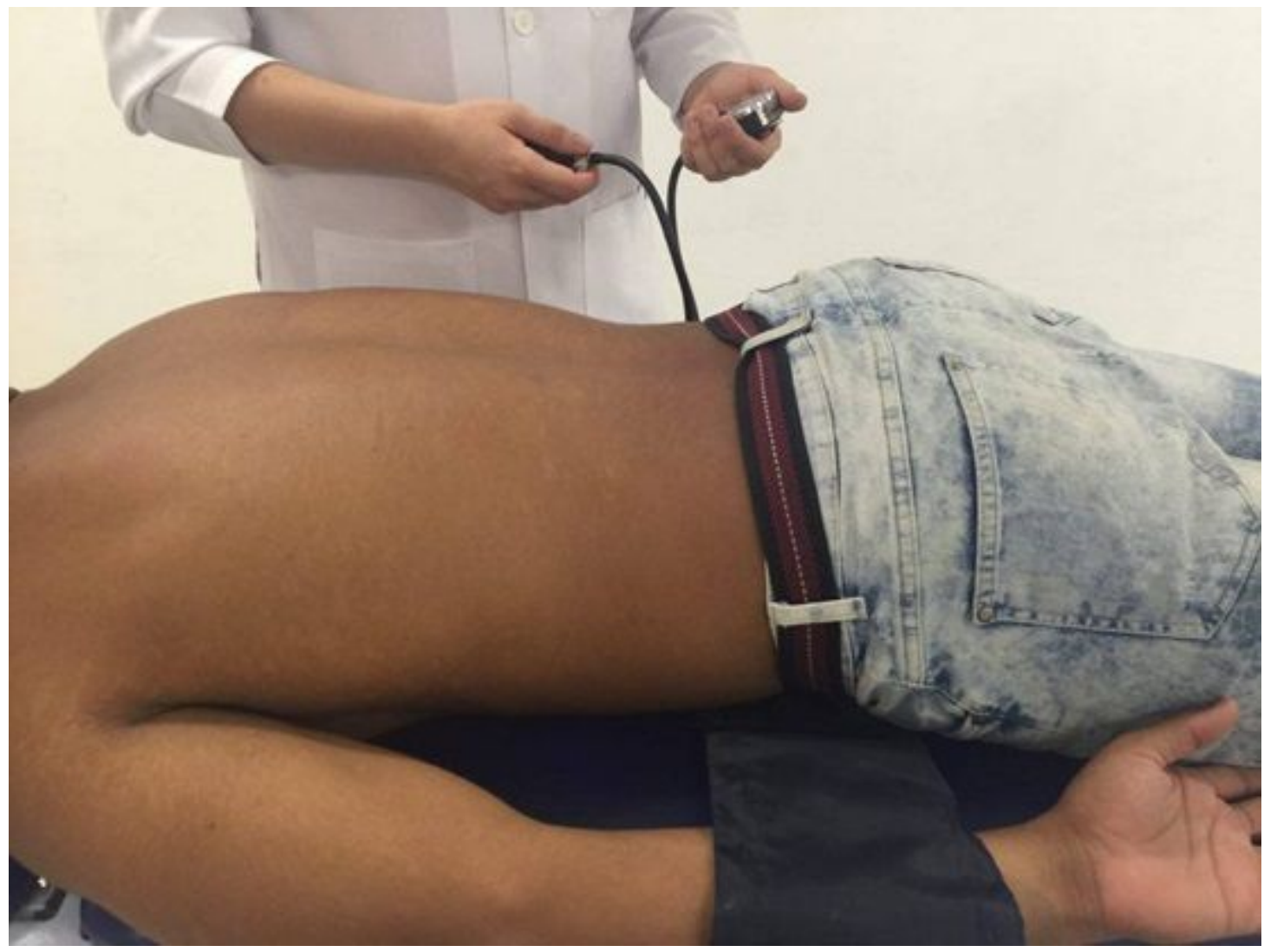

Figure 2 
Muscle activation test for transversus abdominis using a Pressure Biofeedback Unit.

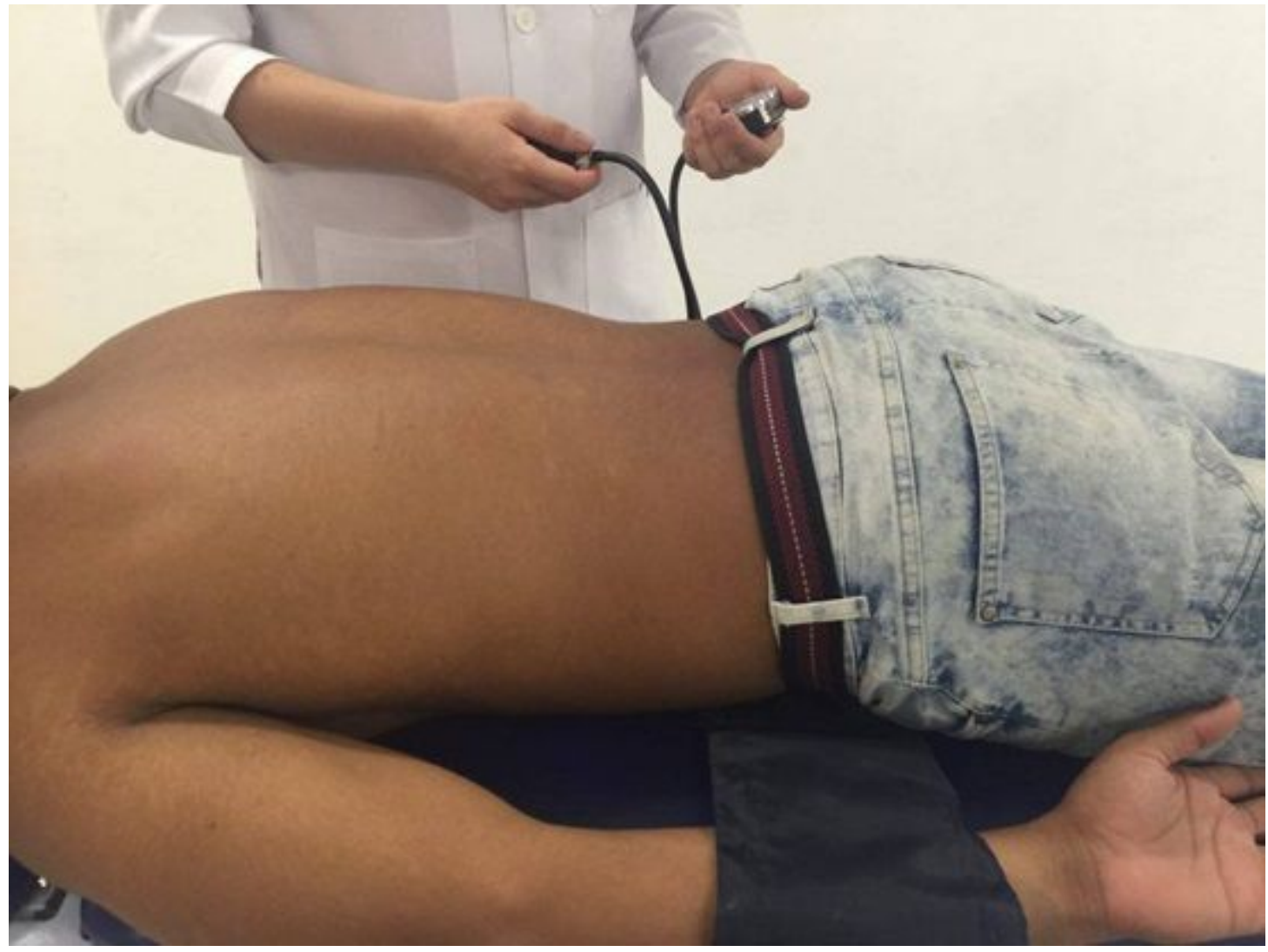

Figure 2

Muscle activation test for transversus abdominis using a Pressure Biofeedback Unit. 